\title{
THE ACCURACY OF TWO EQUATIONS FOR PREDICTING MAXIMAL OXYGEN UPTAKE ON INDIVIDUALIZED RAMP PROTOCOL
}

original paper

(1) University School of Physical Education in Wroclaw

DOI: https://doi.org/10.5114/hm.2018.77323

\author{
PAULA F. AGUIAR ${ }^{1}$, TERENCE A. MORIARTY ${ }^{2}$, WESLEY A. BARACHO ${ }^{1}$, \\ FABRICIO DE PAULA ${ }^{1}$, PAMELA F.M. SAMPAIO ${ }^{1}$, VINICIUS O. OTTONE ${ }^{1}$, \\ MARCO F. DIAS-PEIXOTO ${ }^{1}$, ETEL ROCHA-VIEIRA ${ }^{1}$, FABIANO T. AMORIM ${ }^{1,2}$ \\ ${ }^{1}$ Federal University of Vales do Jequitinhonha e Mucuri, Diamantina, Minas Gerais, Brazil \\ ${ }^{2}$ University of New Mexico, Albuquerque, NM, USA
}

\begin{abstract}
Purpose. Valid protocols use nomograms based on standardized stages to calculate maximal oxygen uptake $\left(\mathrm{VO}_{2} \mathrm{max}\right)$. Although the maximal ramp exercise protocol offers advantages over traditional protocols, it is not known if the non-standardized stages approach affects the accuracy to estimate $\mathrm{VO}_{2} \max$. The study aims to examine the accuracy of 2 equations for predicting $\mathrm{VO}_{2}$ max in a maximal ramp exercise test.

Methods. Overall, 11 men (age: $26 \pm 5$ years, height: $178 \pm 7 \mathrm{~cm}$, weight: $77.6 \pm 9.9 \mathrm{~kg}$ ) underwent 3 sessions of a maximal ramp test on a motorized treadmill; the speed increments were equal but with 0,3 , and $6 \%$ grades. Expired gases were analysed with a portable metabolic system. The $\mathrm{VO}_{2}$ max measured was set as the highest mean value observed from 7 consecutive breaths and it was predicted from 2 equations: American College Sports Medicine (ACSM) and Myers.

Results. VO2max predicted by ACSM equation $\left(54.3 \pm 6.7 \mathrm{~mL} \cdot \mathrm{kg}^{-1} \cdot \mathrm{min}^{-1}\right)$ was approximately $10 \pm 10 \%$ higher and by Myers equation $\left(30.6 \pm 6.1 \mathrm{~mL} \cdot \mathrm{kg}^{-1} \cdot \mathrm{min}^{-1}\right)$ approximately $38 \pm 11 \%$ lower than directly measured $\left(49.6 \pm 6.7 \mathrm{~mL} \cdot \mathrm{kg}^{-1} \cdot \mathrm{min}^{-1}, p<\right.$ 0.05). Bland-Altman graphs indicate low and no agreement for ACSM and Myers equations, respectively. The calculated standard error of the estimates was $6.5 \mathrm{~mL} \cdot \mathrm{kg}^{-1} \cdot \mathrm{min}^{-1}$ for ACSM equation and $19.9 \mathrm{~mL} \cdot \mathrm{kg}^{-1} \cdot \mathrm{min}^{-1}$ for Myers equation. Conclusions. The ACSM and Myers equations significantly over- and under-predict the $\mathrm{VO}_{2}$ max of young adults, respectively. Although the former overestimated $\mathrm{VO}_{2} \mathrm{max}$, we recommend its use with caution.
\end{abstract}

Key words: exercise testing, $\mathrm{VO}_{2} \max$, ramp test, prediction equations

\section{Introduction}

For over half a century, maximal exercise stress testing has been the most widely used non-invasive tool to provide diagnostic and prognostic information of an individual's cardiovascular, pulmonary, and muscular systems [1]. Maximal exercise stress testing typically occurs on a motorized treadmill [2] with the individual achieving voluntary fatigue. There are several exercise testing protocols performed on the treadmill, such as Bruce [3], Ellestad [4], and Naughton [5]. The established guidelines recommend that exercise testing protocols should consider the purpose of the test and characteristics of the individual to be tested (exercise prescription, sports training, or clinical evaluation), and have small gradual increments in workload in order to present a more linear relationship between the measured oxygen uptake and work rate $[1,6]$.

Most of the traditional exercise testing protocols mentioned above use large increments in workload per stage (> 1 MET), a non-individualized approach, and test duration outside of the recommended 8-12-minute range [7-9]. Developed by Whipp et al. [10], the individualized ramp protocol, which allows customized constant and modest increases in workload per stage (resistance on cycle ergometer or speed and grade on

Correspondence address: Terence Anthony Moriarty, University of New Mexico, 1150 Johnson Center MSC04 2610, Albuquerque, New Mexico 87131, USA, e-mail: moria1ta@unm.edu

Received: March 22, 2018

Accepted for publication: July 4, 2018

Citation: Aguiar PF, Moriarty TA, Baracho WA, de Paula F, Sampaio PFM, Ottone VO, Dias-Peixoto MF, Rocha-Vieira E, Amorim FT. The accuracy of two equations for predicting maximal oxygen uptake on individualized ramp protocol. Hum Mov. 2018;19(4):42-48; doi: https://doi.org/10.5114/hm.2018.77323. 
treadmill), results in a more uniform increase in hemodynamic and physiologic responses and accurate estimates of exercise capacity and ventilatory threshold [6]. Additionally, this protocol is nowadays widely used in clinical settings, both in healthy, active populations and in clinical patients [11], and recommended by the American College of Sports Medicine (ACSM) [7] and the American Heart Association [12].

One of the parameters acquired from all maximal exercise testing protocols mentioned above is maximal oxygen uptake $\left(\mathrm{VO}_{2} \mathrm{max}\right)$, related to the limits of the cardiopulmonary and musculoskeletal systems [3]. $\mathrm{VO}_{2}$ max is obtained by the direct measurement of expired gases and ventilatory responses during exercise, usually through computerized metabolic cart systems. However, the equipment costs, time demands, and need for trained technicians discourage the use of direct measurement in clinical settings. Another way to obtain $\mathrm{VO}_{2}$ max is by converting the maximal achieved workload using previously developed regression equations. The association between measured and predicted oxygen uptake, based on a previous study, suggests that the individualized ramp protocol has advantages over other protocols when the need for predicting oxygen uptake exists [13].

Regarding the individualized ramp protocol, there are 2 equations recommended by the ACSM to calculate $\mathrm{VO}_{2}$ max. The first is the Myers et al. [13] regression equation, which was developed on the basis of data acquired when using a ramp protocol among 200 middle age healthy and hypertensive (24\% of the subjects) adults. The other prediction equations are the ACSM walking or running metabolic equations, developed for submaximal steady-state exercise [7] and used by some stress testing manufacturer companies (e.g. Burdick corporation, Milwaukee, USA). Recent evidence has shown that the ACSM walking or running equations [7] are not capable of accurately predicting $\mathrm{VO}_{2} \max$ in athletes using the Bruce protocol [14]. This is due to the increases in workload irrespective of steady-state oxygen consumption. Additionally, it is not known if these equations are valid and accurate to predict $\mathrm{VO}_{2}$ max in individualized maximal ramp protocols. Therefore, this study examined the accuracy of 2 equations for predicting $\mathrm{VO}_{2}$ max in young adults using an individualized ramp protocol. It was hypothesized that the Myers et al. [13] and ACSM [7] equations would not accurately predict the $\mathrm{VO}_{2} \max$ of healthy young individuals using an individualized ramp protocol.

\section{Material and methods}

\section{Subjects}

The total of 11 young healthy male (mean age, height, and weight were $26 \pm 5$ years, $178 \pm 7 \mathrm{~cm}$, and $77.6 \pm$ $9.9 \mathrm{~kg}$, respectively), physically active (according to a physical activity questionnaire - minimum 150 minutes of moderate physical activity as per ACSM guidelines), non-smoking volunteers were recruited at a university, as well as the surrounding community; 4 subjects were amateur athletes (training frequency: $\geq 5$ days per week) and 7 subjects were engaged in running/cycling and/or resistance training (training frequency: 3-4 days per week). They did not have a previous history of fainting, nausea, or musculoskeletal discomfort during exercise.

\section{$\mathrm{VO}_{2}$ max measurement}

Each subject completed $3 \mathrm{VO}_{2}$ max ramp tests using different fixed grades $(0,3$, and $6 \%)$ but equal speed increments (on average $0.92 \pm 0.17 \mathrm{~km} \cdot \mathrm{h}^{-1}$ ) under temperate conditions $\left(19.5^{\circ} \mathrm{C} \pm 0.7\right.$ and $53 \pm 8 \%$ air relative humidity). The purpose of the 3 different fixed grades, but equal speed increments was to increase the number of $\mathrm{VO}_{2}$ max measurements per subject and, consequently, calculations per subject using the 2 prediction equations. Additionally, we tested if different ramp protocol designs (3 different grades; 0,3 , and $6 \%$ ) would interfere with $\mathrm{VO}_{2}$ max prediction. The initial speed was $6.0 \pm 1.2 \mathrm{~km} \cdot \mathrm{h}^{-1}$ (varying from 5.0 to $9.0 \mathrm{~km} \cdot \mathrm{h}^{-1}$ ) and the final speed was $16.1 \pm$ $2.2 \mathrm{~km} \cdot \mathrm{h}^{-1}$ (varying from 13.0 to $20.0 \mathrm{~km} \cdot \mathrm{h}^{-1}$ ). These speeds were based on the estimated physical fitness of the volunteers. The tests were performed in a counter-balanced order and separated by at least 48 hours (but not more than 7 days). Exercise testing was performed on a semi-computer-controlled treadmill (PRO 300 RT, Movement, São Paulo, Brazil). The ramp protocol began with a 3 -minute warm-up at $5 \mathrm{~km} \cdot \mathrm{h}^{-1}$. Then, the grade was set at a fixed value $(0,3$, or $6 \%)$ and speed was increased at an individual rate until voluntary fatigue was reached. Verbal encouragement was given throughout the test. The speed increments occurred every 60 seconds and were based on the results of the physical activity questionnaire to induce volitional fatigue between 8 and 12 minutes [9]. The subjects were blinded to the speed, grade, and time elapsed on the tests. The Borg rating of perceived exertion (RPE) scale (6-20) was used to quantify the level of exertion at each minute. At the point of maximal exhaustion, the grade was removed, and the speed was 
reduced to $5 \mathrm{~km} \cdot \mathrm{h}^{-1}$. After 3 minutes at $5 \mathrm{~km} \cdot \mathrm{h}^{-1}$, the treadmill was stopped, and the volunteer remained seated for a period of 10 minutes.

During each test, expired air was analysed in a breath-by-breath format by a portable metabolic cart (K4b2, Cosmed, Rome, Italy). The calibration of airflow, volumes, and both the $\mathrm{O}_{2}$ and $\mathrm{CO}_{2}$ occurred immediately before each test as recommended by the manufacturer. Heart rate (HR) was recorded every 5 seconds with a short-range telemetry apparatus (F4 Blk, Polar, Kempele, Finland). A blood sample of $25 \mu \mathrm{L}$ was collected from the finger tip for lactate concentration measurement at 30 seconds into the recovery phase (Accusport, Boehringer Mannheim, Castle Hill, Australia). Maximal oxygen consumption was determined by the attainment of at least 3 of the following five criteria: (1) a plateau (delta $\mathrm{VO}_{2}<50 \mathrm{~mL} \cdot \mathrm{min}^{-1}$ at $\mathrm{VO}_{2}$ peak) in $\mathrm{VO}_{2}$ with increases in external work, (2) maximal respiratory exchange ratio (RER) > 1.15, (3) maximal $\mathrm{HR}>$ $95 \%$ of the maximum age-predicted value (220 - age), (4) blood lactate over $8 \mathrm{mmol} \cdot \mathrm{min}^{-1}$, and (5) RPE over 18 [9].

\section{Predicted $\mathrm{VO}_{2}$ max calculation}

$\mathrm{VO}_{2}$ max was calculated on the basis of the speed and grade of the last completed 1-minute stage of the 3 tests ( 0,3 , and $6 \%$ grade) with the following equations:

\section{ACSM running equation [7]:}

$\mathrm{VO}_{2}\left[\mathrm{~mL} \cdot \mathrm{kg}^{-1} \cdot \mathrm{min}^{-1}\right]=0.2\left(\right.$ speed $\left.\left[\mathrm{m} \cdot \mathrm{s}^{-1}\right]\right)+$ 0.9 (speed $\left.\left[\mathrm{m} \cdot \mathrm{s}^{-1}\right]\right)$ (fractional grade) +3.5

\section{Myers et al. equation [13]:}

$$
\begin{gathered}
\mathrm{VO}_{2}\left[\mathrm{~mL} \cdot \mathrm{kg}^{-1} \cdot \mathrm{min}^{-1}\right]=0.72\left(\mathrm{VO}_{2}\right. \text { calculated } \\
\text { by ACSM running equation })+3.67
\end{gathered}
$$

\section{Statistical analyses}

All data were analysed with the Statistica software (version 7.0 for Windows). The Shapiro-Wilk test indicated that the data were normally distributed. Sphericity was also checked, and the data did not violate this assumption for one-way analysis of variance (ANOVA). Statistical analyses included Pearson product moment correlations to establish relationships between predicted and measured values, and ANOVA with repeated measures to determine significant differences between predicted and measured $\mathrm{VO}_{2}$ max means. If a significant $\mathrm{F}$ ratio was obtained in the ANOVA test, Tukey's honestly significant difference (HSD) test was used to locate differences between the means. Statistical significance was set at the alpha level of 0.05. BlandAltman graphs were applied with measured $\mathrm{VO}_{2}$ max plotted on the x-axis, and the difference between the $\mathrm{VO}_{2}$ max predicted with the use of the ACSM [7] and Myers et al. [13] equations and $\mathrm{VO}_{2}$ max measured directly plotted on the y-axis. The upper and lower 1-MET agreement lines were indicated in the BlandAltman graphs. On the basis of our sample size and alpha of 0.05 , we achieved the statistical power of 0.97 . All graphical representations were made with the Prism 3.0 software.

\section{Ethical approval}

The research related to human use has been complied with all the relevant national regulations and institutional policies, has followed the tenets of the Declaration of Helsinki, and has been approved by the Institutional Review Board on Human Experimentation of the University Center of Belo Horizonte, Brazil (protocol 008/2009).

\section{Informed consent}

Informed consent has been obtained from all individuals included in this study.

\section{Results}

All subjects performed the 3 exercise stress tests until voluntary fatigue without any complications. The actual test duration varied from a minimum of 6:30 to a maximum of 15:01 minutes. The subject characteristics and physiological responses of the maximal ramp exercise test are presented in Table 1.

The $\mathrm{VO}_{2}$ max results which were measured directly and predicted by the 2 equations are presented in Figure 1. The average $\mathrm{VO}_{2}$ max measured directly $(49.6 \pm$ $\left.6.7 \mathrm{~mL} \cdot \mathrm{kg}^{-1} \cdot \mathrm{min}^{-1}\right)$ was lower $(p=0.01$; mean differ-

Table 1. Subject characteristics and physiological responses during the maximal ramp exercise test

$$
(n=33)
$$

\begin{tabular}{lc}
\hline Variable & Mean $\pm S D$ \\
\hline Test duration $(\mathrm{min})$ & $10: 06 \pm 2: 04$ \\
Maximum running speed $\left(\mathrm{km} \cdot \mathrm{h}^{-1}\right)$ & $13.9 \pm 2.1$ \\
Maximum oxygen consumption & $49.6 \pm 6.7$ \\
$\left(\mathrm{~mL} \cdot \mathrm{kg}^{-1} \cdot \mathrm{min}^{-1}\right)$ & \\
Maximum ventilation $\left(\mathrm{L} \cdot \mathrm{min}^{-1}\right)$ & $151.4 \pm 29.8$ \\
Respiratory exchange ratio $(\mathrm{RER})$ & $1.21 \pm 0.07$ \\
Lactate concentration $\left(\mathrm{mmol} \cdot \mathrm{l}^{-1}\right)$ & $9.2 \pm 3.6$ \\
Maximum heart rate achieved $\left(\mathrm{b} \cdot \mathrm{min}^{-1}\right)$ & $186 \pm 7$ \\
Percentage of maximum age-predicted & $101 \pm 3$ \\
$\quad$ heart rate $(220-$ age $)$ & \\
\hline
\end{tabular}




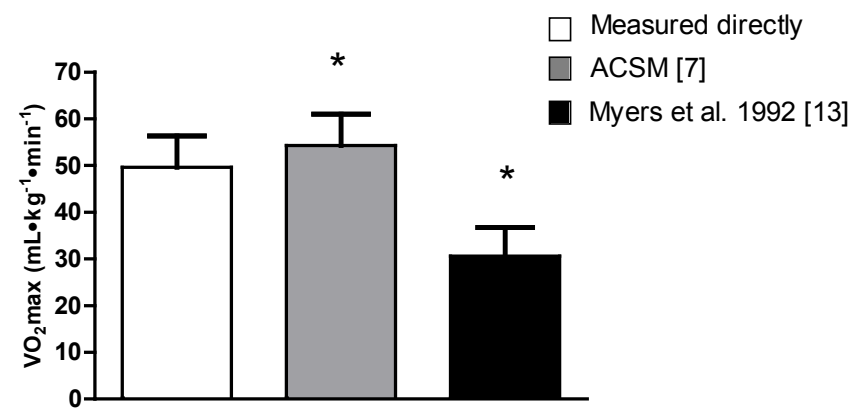

* significant difference $(p<0.05)$ between the ACSM [7] and Myers et al. [13] equations vs. direct measurement

Figure $1 . \mathrm{VO}_{2}$ max measured directly and calculated by the ACSM [7] and Myers et al. [13] equations (mean $\pm S D, n=33$ )

Table 2. $\mathrm{VO}_{2} \max \left(\mathrm{mL} \cdot \mathrm{kg}^{-1} \cdot \mathrm{min}^{-1}\right)$ measured directly and calculated by the ACSM [7] and Myers et al. [13] equations in the 3 differing graded ramp tests (mean $\pm S D, n=33$ )

\begin{tabular}{lccc}
\cline { 2 - 4 } & $0 \%$ & $3 \%$ & $6 \%$ \\
\hline Direct measurement & $48.2 \pm 6.1$ & $49.7 \pm 6.6$ & $50.9 \pm 7.6$ \\
ACSM [7] & $53.2 \pm 7.2$ & $54.3 \pm 6.4$ & $55.4 \pm 6.3$ \\
Myers et al. [13] & $24.1 \pm 2.7$ & $31.0 \pm 3.1$ & $36.8 \pm 3.7$ \\
\hline
\end{tabular}

ence: $-4.7 \pm 4.6 \mathrm{~mL} \cdot \mathrm{kg}^{-1} \cdot \mathrm{min}^{-1}$ ) than the value predicted by the ACSM running equation [7] (54.3 \pm 6.7 $\left.\mathrm{mL} \cdot \mathrm{kg}^{-1} \cdot \mathrm{min}^{-1}\right)$ and higher $(p<0.001$; mean difference: $19 \pm 6.2 \mathrm{~mL} \cdot \mathrm{kg}^{-1} \cdot \mathrm{min}^{-1}$ ) than the value predicted by the Myers et al. [13] equation $\left(30.6 \pm 6.1 \mathrm{~mL} \cdot \mathrm{kg}^{-1} \cdot \mathrm{min}^{-1}\right)$.

The $\mathrm{VO}_{2}$ max results from 0,3 , and $6 \%$ grade $\left(48.2 \pm 6.1,49.7 \pm 6.6\right.$, and $50.9 \pm 7.6 \mathrm{~mL} \cdot \mathrm{kg}^{-1} \cdot \mathrm{min}^{-1}$, respectively) were not statistically different $(p>0.05)$ (Table 2). Analysing the 3 different grades separately did not affect prediction for the ACSM equation [7], as it varied from 9 to $10 \%$ compared with $10 \%$ with all 3 grades together. Also, $\mathrm{VO}_{2}$ max predicted by the ACSM equation [7] was not different between the 3 different

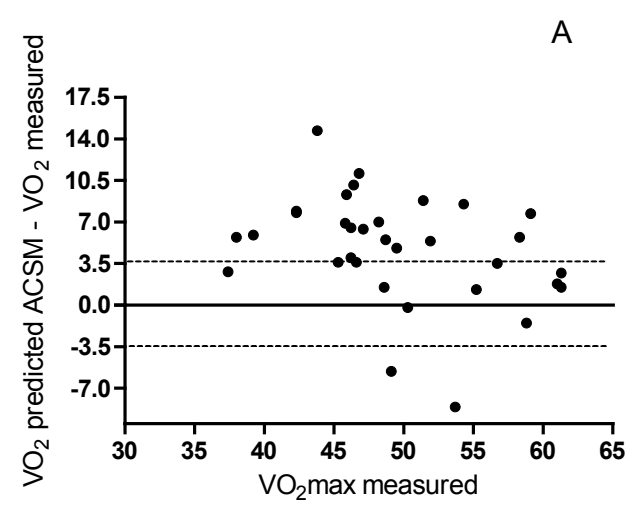

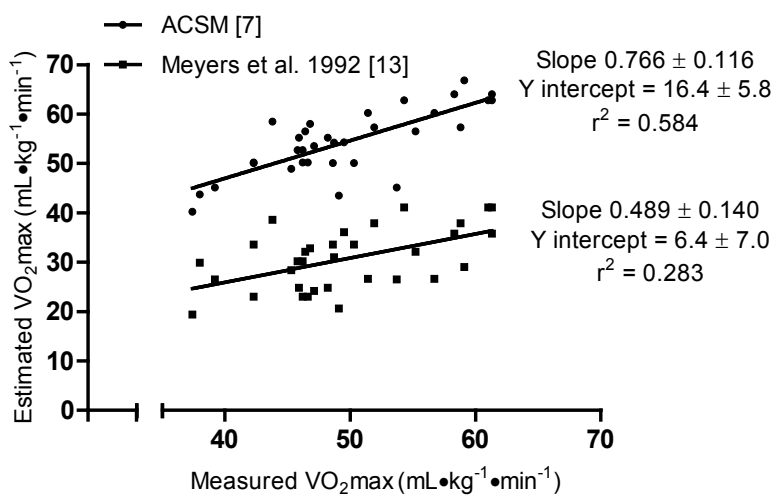

Figure 2. Relationship between $\mathrm{VO}_{2}$ max measured directly and calculated by the ACSM [7]

and Myers et al. [13] equations (mean $\pm S D, n=33$ )

grades $(0,3$, and $6 \%$ grades, $p=0.09)$. However, for the Myers et al. [13] equation, we observed a large difference when analysing each grade separately (from 27.7 to $50 \%$ ) compared with all 3 grades together (ca. $38 \%$ ). Moreover, $\mathrm{VO}_{2}$ max predicted by the Myers et al. [13] equation was higher for $6 \%$ compared with $3 \%$ $(p<0.001)$ and $0 \%$ grade $(p<0.001)$ and higher for $3 \%$ compared with $0 \%$ grade $(p<0.001)$.

The relationship between all measured and predicted $\mathrm{VO}_{2}$ max values throughout the exercise protocols are shown in Figure 2. The $\mathrm{VO}_{2}$ max measured directly positively correlated with the ACSM running [7] $(r=$ $\left.0.76, r^{2}=0.58, p<0.001\right)$ and Myers et al. [13] $(r=0.53$, $\left.r^{2}=0.28, p=0.001\right)$ equations. The standard errors of the estimates were 6.5 and $19.9 \mathrm{~mL} \cdot \mathrm{kg}^{-1} \cdot \mathrm{min}^{-1}$ for the ACSM running [7] and Myers et al. [13] equations, respectively. The Bland-Altman graph for the ACSM running [7] equation (Figure 3A) indicates that it has poor agreement and a tendency to overestimate $\mathrm{VO}_{2}$ max. In addition, the Bland-Altman graph for the Myers et al. [13] equation (Figure 3B) reveals that it has no agreement and underestimates $\mathrm{VO}_{2} \max$.

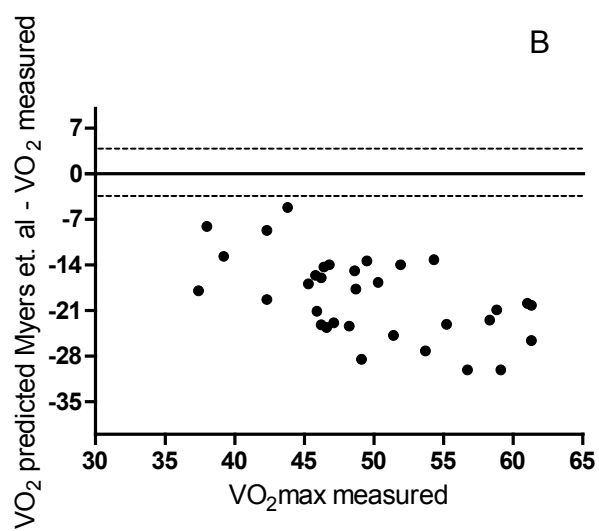

Figure 3. Bland-Altman plots of $\mathrm{VO}_{2}$ max predicted with the ACSM [7] (A) and Myers et al. [13] (B) equations and $\mathrm{VO}_{2}$ max measured directly. Dotted lines display upper and lower limits of agreement with $1 \mathrm{MET}\left(3.5 \mathrm{~mL} \cdot \mathrm{kg}^{-1} \cdot \mathrm{min}^{-1}\right)$ (mean $\pm S D, n=33$ ) 


\section{Discussion}

The present study examined the accuracy of 2 equations recommended for predicting $\mathrm{VO}_{2}$ max in an individualized ramp protocol. The most important aspect of the study was to compare the extent of the errors produced in the prediction equations with measured $\mathrm{VO}_{2}$ max values to make a recommendation on whether or not these methods should be employed in everyday exercise settings. Our results indicate that $\mathrm{VO}_{2}$ max is over- and under-predicted with the ACSM running [7] and Myers et al. [13] equations, respectively. The authors believe that several factors may have played a role in this result and these are discussed in detail below. This result undermines the use of these specific metabolic equations in predicting $\mathrm{VO}_{2} \max$.

It was observed that the ACSM equation [7] overpredicted the $\mathrm{VO}_{2}$ max by approximately $10 \%$. In this case, the standard error of the estimate (SEE) $\left(6.5 \mathrm{~mL} \cdot \mathrm{kg}^{-1} \cdot \mathrm{min}^{-1}\right)$ indicates a poor accuracy of the ACSM equation [7]. Additionally, the upper and lower 1-MET agreement lines in the Bland-Altman plots (Figure $3 \mathrm{~A}$ ) show that only $33 \%$ of the $\mathrm{VO}_{2}$ max values predicted with the ACSM equation [7] were within the 1-MET limit. A number of previous studies have evaluated the accuracy of the ACSM equations. Peterson et al. [15] found that the ACSM equation [7] overpredicted $\mathrm{VO}_{2} \max$ (by approximately $20 \%$ ) when the Pepper protocol was applied, and concluded that it was not appropriate for use when testing older adults. Foster et al. [16] also observed a significant difference between estimated and measured $\mathrm{VO}_{2}$ max values $\left(55.3 \pm 16.4\right.$ vs. $47.1 \pm 14.6 \mathrm{~mL} \cdot \mathrm{kg}^{-1} \cdot \mathrm{min}^{-1}$, respectively, $p<0.01$ ) in a group of individuals with heterogeneous exercise capacities (from very debilitated patients to competitive athletes) using a protocol similar to the ramp one. The authors noted a significant relationship between the estimated and predicted VO${ }_{2} \max \left(r^{2}=0.995\right)$ and the SEE of $4.8 \mathrm{~mL} \cdot \mathrm{kg}^{-1} \cdot \mathrm{min}^{-1}$. More recently, Koutlianos et al. [14] also found that the ACSM equation [7] was not capable of accurately predicting $\mathrm{VO}_{2}$ max in athletes using the Bruce protocol. Alternatively, the authors developed a regression model that correlated moderately with the measured values of $\mathrm{VO}_{2}$ max. It should be noted that the ACSM equation [7] was developed for submaximal steady-state exercise (including protocols of 2-3 minutes or more in duration), and in the ramp protocol, owing to its nature, the $\mathrm{VO}_{2}$ response is specific to the non-steady-state conditions. Additionally, the aforementioned previous studies used different maximal exercise protocols and populations and have found a statistical difference among measured and predicted $\mathrm{VO}_{2}$ max values. Taken together, the reported differences in the results of applying the $\mathrm{VO}_{2}$ max prediction equations are most likely due to the use of exercise protocols and intensities (non-steady state exercise) other than those for which the equations were actually intended (continuous steady-state exercise).

The Myers et al. [13] equation under-predicted $\mathrm{VO}_{2}$ max by approximately $38 \%$. The upper and lower 1-MET agreement lines in the Bland-Altman plots (Figure 3B) show that none of the $\mathrm{VO}_{2}$ max values predicted with the Myers et al. [13] equation were within the 1-MET limit. In the original study, Myers et al. [13] involved fit $\left(\mathrm{VO}_{2} \max\right.$ of $\left.33.1 \mathrm{~mL} \cdot \mathrm{kg}^{-1} \cdot \mathrm{min}^{-1}\right)$ middle aged (ca. 43 years old on average) hypertensive ( $24 \%$ of the subjects) and normotensive participants. The authors predetermined the speed on the basis of the peak treadmill walking speed, which resulted in low speed $\left(5.3 \mathrm{~km} \cdot \mathrm{h}^{-1}\right)$ and high grade $(16 \%)$ during the tests. This high grade may have changed the walking efficiency (handrail holding) of the subjects and resulted in a greater degree of error when predicting $\mathrm{VO}_{2} \max$ on the lower treadmill grade. In the present study, we used young healthy active males, running with a preset grade and high speed $\left(13.9 \pm 2.1 \mathrm{~km} \cdot \mathrm{h}^{-1}\right)$. These protocol characteristics may account for the observed differences and low correlation between the predicted and measured $\mathrm{VO}_{2} \max$ herein. Additionally, the Myers et al. [13] regression equation is derived from the ACSM equation [7] and may inflate the magnitude of the error and lower agreement with the measured $\mathrm{VO}_{2}$ max. Thus, caution is recommended when using this equation with protocols and groups of individuals with characteristics different from those in the original study.

The use of 3 different grades $(0,3$, and $6 \%)$ in this ramp protocol style did not affect the $\mathrm{VO}_{2}$ max values which were measured directly (Table 2). Contrary to this finding, Mayhew and Gross [17] reported higher measured $\mathrm{VO}_{2}$ max values when grade was present $\left(69.0 \pm 4.6 \mathrm{~mL} \cdot \mathrm{kg}^{-1} \cdot \mathrm{min}^{-1}\right)$ compared with the nongrade test $\left(66.9 \pm 5.3 \mathrm{~mL} \cdot \mathrm{kg}^{-1} \cdot \mathrm{min}^{-1}\right)$. However, the protocol used was different from that in the present study: the speed was increased every 2 minutes and the speed increments were not similar between tests (grade vs. non-grade). The 3 different grades used in the present study did not affect $\mathrm{VO}_{2}$ max prediction with the ACSM equation [7]. However, a greater variation in $\mathrm{VO}_{2}$ max prediction was observed for the Myers et al. [13] equation (from 27 to 50\%). In both prediction calculations, closer predicted $\mathrm{VO}_{2}$ max values to the measured ones were present at $6 \%$ grade. This 
indicates that grade (or vertical component) is an important factor when predicting $\mathrm{VO}_{2}$ max with both equations.

A possible limitation of the design described herein was the use of 3 tests for the same subject. Our intention was to increase the number of measurements per subject in order to allow more samples of directly measured and predicted $\mathrm{VO}_{2} \max$ values. A recent study [18] compared the efficacy of a ramp incremented protocol and an RPE-clamped test (consisting of five 2-minute stages where subjects self-selected the work rate) protocol for eliciting $\mathrm{VO}_{2}$ max and found no difference, therefore indicating that the work rate did not change $\mathrm{VO}_{2} \max$ on the same duration test $(568 \pm 72 \mathrm{~s}$ in the ramp protocol and $600 \pm 0 \mathrm{~s}$ in the RPE-clamped protocol). Additionally, the subjects in our study were physically active and healthy for the majority, and thus our findings need to be verified in sedentary and nonhealthy populations. Furthermore, in some studies using a ramp protocol, grade began to increase once the prespecified maximum speed was achieved by a subject. In the present study, grade was fixed from the beginning of the exercise test. This procedure was necessary to guarantee 3 different graded exercise tests. However, we believe that this methodological approach may have interfered with the $\mathrm{VO}_{2}$ max values directly observed or predicted.

\section{Conclusions}

The results indicate that the ACSM [7] and Myers et al. [13] equations over- and under-predict the $\mathrm{VO}_{2} \max$ of young adults in a maximal ramp protocol, respectively. Although the ACSM equation overestimated $\mathrm{VO}_{2}$ max compared with direct measurements, we recommend its use with caution. In the case of a precise value of $\mathrm{VO}_{2}$ max being required, we recommend direct measurements. Further studies are needed to determine the effectiveness of the ACSM equation in populations with characteristics different from those studied herein.

\section{Disclosure statement}

No author has any financial interest or received any financial benefit from this research.

\section{Conflict of interest}

The authors state no conflict of interest.

\section{References}

1. Balady GJ, Arena R, Sietsema K, Myers J, Coke L, Fletcher GF, et al. Clinician's guide to cardiopulmonary exercise testing in adults: a scientific statement from the American Heart Association. Circulation. 2010;122(2): 191-225; doi: 10.1161/CIR.0b013e3181e52e69.

2. Myers J, Voodi L, Umann T, Froelicher VF. A survey of exercise testing: methods, utilization, interpretation, and safety in the VAHCS. J Cardiopulm Rehabil. 2000; 20(4):251-258; doi: 10.1097/00008483-20000700000007.

3. Bruce RA. Exercise testing of patients with coronary heart disease. Principles and normal standards for evaluation. Ann Clin Res. 1971;3(6):323-332.

4. Ellestad MH. Stress testing, $2^{\text {nd }}$ ed. Philadelphia: F.A. Davis; 1980.

5. Patterson JA, Naughton J, Pietras RJ, Gunnar RM. Treadmill exercise in assessment of the functional capacity of patients with cardiac disease. Am J Cardiol. 1972; 30(7):757-762; doi: 10.1016/0002-9149(72)90151-8.

6. Myers J, Buchanan N, Walsh D, Kraemer M, McAuley P, Hamilton-Wessler M, et al. Comparison of the ramp versus standard exercise protocols. J Am Coll Cardiol. 1991;17(6):1334-1342; doi: 10.1016/S0735-1097(10) 80144-5.

7. American College of Sports Medicine. ACSM's guidelines for exercise testing and prescription, $9^{\text {th }} \mathrm{ed}$. Baltimore: Lippincott Williams \& Wilkins; 2013.

8. Buchfuhrer MJ, Hansen JE, Robinson TE, Sue DY, Wasserman K, Whipp BJ. Optimizing the exercise protocol for cardiopulmonary assessment. J Appl Physiol Respir Environ Exerc Physiol. 1983;55(5):1558-1564; doi: 10.1152/jappl.1983.55.5.1558.

9. Yoon BK, Kravitz L, Robergs R. VO2max, protocol duration, and the VO2 plateau. Med Sci Sports Exerc. 2007; 39(7):1186-1192; doi: 10.1249/mss.0b13e318054e304.

10. Whipp BJ, Davis JA, Torres F, Wasserman K. A test to determine parameters of aerobic function during exercise. J Appl Physiol Respir Environ Exerc Physiol. 1981; 50(1):217-221; doi: 10.1152/jappl.1981.50.1.217.

11. Boone J, Bourgois J. The oxygen uptake response to incremental ramp exercise: methodogical and physiological issues. Sports Med. 2012;42(6):511-526; doi: 10.2165/11599690-000000000-00000.

12. American Heart Association. Guidelines for CPR and ECC. Circulation. 2010;122:S639; doi: 10.1161/CIR. 0b013e3181fdf7aa.

13. Myers J, Buchanan N, Smith D, Neutel J, Bowes E, Walsh D, et al. Individualized ramp treadmill: observations on a new protocol. Chest. 1992;101(5 Suppl): 236S241S; doi: 10.1378/chest.101.5_Supplement.236S.

14. Koutlianos N, Dimitros E, Metaxas T, Cansiz M, Deligiannis A, Kouidi E. Indirect estimation of VO2max in athletes by ACSM's equation: valid or not? Hippokratia. 2013;17(2):136-140.

15. Peterson MJ, Pieper CF, Morey MC. Accuracy of VO2(max) prediction equations in older adults. Med Sci 


\section{HUMAN MOVEMENT}

P.F. Aguiar et al., Predicting maximal oxygen uptake

Sports Exerc. 2003;35(1):145-149; doi: 10.1249/01. MSS.0000043547.22724.0B.

16. Foster C, Crowe AJ, Daines E, Dumit M, Green MA, Lettau S, et al. Predicting functional capacity during treadmill testing independent of exercise protocol. Med Sci Sports Exerc. 1996;28(6):752-756; doi: 10.1097/ 00005768-199606000-00014.

17. Mayhew JL, Gross PM. Comparison of grade-incremented versus speed-incremented maximal exercise tests in trained men. Br J Sports Med. 1975;9(4):191195; doi: 10.1136/bjsm.9.4.191.

18. Straub AM, Midgley AW, Zavorsky GS, Hillman AR. Ramp-incremented and RPE-clamped test protocols elicit similar VO2max values in trained cyclists. Eur J Appl Physiol. 2014;114(8):1581-1590; doi: 10.1007/ s00421-014-2891-0. 